\title{
Posing Researchable Questions in Mathematics and Science Education: Purposefully Questioning the Questions for Investigation
}

\author{
Jinfa Cai ${ }^{1} \cdot$ Rachel Mamlok-Naaman ${ }^{2}$ \\ Published online: 7 April 2020 \\ (C) Ministry of Science and Technology, Taiwan 2020
}

Perhaps the most obvious example is the set of 23 influential mathematical problems posed by David Hilbert that inspired a great deal of progress in the discipline of mathematics (Hilbert, 1901-1902). Einstein and Infeld (1938) claimed that "to raise new questions, new possibilities, to regard old problems from a new angle, requires creative imagination and marks real advance in science" (p. 95). Both Cantor and Klamkin recommended that, in mathematics, the art of posing a question be held as high or higher in value than solving it. Similarly, in the history of science, formulating precise, answerable questions not only advances new discoveries but also gives scientists intellectual excitement (Kennedy, 2005; Mosteller, 1980).

In research related to mathematics and science education, there is no shortage of evidence for the impact of posing important and researchable questions: Posing new, researchable questions marks real advances in mathematics and science education (Cai et al., 2019a). Although research in mathematics and science education begins with researchable questions, only recently have researchers begun to purposefully and systematically discuss the nature of researchable questions. To conduct research, we must have researchable questions, but what defines a researchable question? What are the sources of researchable questions? How can we purposefully discuss researchable questions?

This special issue marks effort for the field's discussion of researchable questions. As the field of mathematics and science education matures, it is necessary to reflect on the field at such a metalevel (Inglis \& Foster, 2018). Although the authors in this special issue discuss researchable questions from different angles, they all refer to researchable questions as those that can be investigated empirically. For any empirical study, one can discuss its design, its conduct, and how it can be written up for publication. Therefore,

Jinfa Cai

jcai@udel.edu

1 University of Delaware, Newark, DE, USA

2 Weizmann Institute of Science, Rehovot, Israel 
researchable questions in mathematics and science education can be discussed with respect to study design, the conduct of research, and the dissemination of that research.

Even though there are many lines of inquiry that we can explore with respect to researchable questions, each exploring the topic from a different angle, we have decided to focus on the following three aspects to introduce this special issue: (1) criteria for selecting researchable questions, (2) sources of researchable questions, and (3) alignment of researchable questions with the conceptual framework as well as appropriate research methods.

\section{Criteria for Selecting Researchable Questions}

It is clear that not all researchable questions are worth the effort to investigate. According to Cai et al. (2020), of all researchable questions in mathematics and science education, priority is given to those that are significant. Research questions are significant if they can advance the fields' knowledge and understanding about the teaching and learning of science and mathematics. Through an analysis of peer reviews for a research journal, Cai et al. (2020) provide a window into the field's frontiers related to significant researchable questions. In an earlier article, Cai et al. (2019a) argued that

The significance of a research question cannot be determined just by reading it. Rather, its significance stands in relation to the knowledge of the field. The justification for the research question itself - why it is a significant question to investigate - must therefore be made clear through an explicit argument that ties the research question to what is and is not already known. (p. 118)

In their analysis, Cai et al. (2020) provide evidence that many reviews that highlighted issues with the research questions in rejected manuscripts specifically called for authors to make an argument to motivate the research questions, whereas none of the manuscripts that were ultimately accepted (pending revisions) received this kind of comment. Cai et al. (2020) provide a framework not only for analyzing peer reviews about research questions but also for how to communicate researchable questions in journal manuscript preparations.

Whereas Cai and his colleagues, as editors of a journal, discuss significant research questions from the perspective of peer review and publication, King, Ochsendorf, Solomon, and Sloane (2020), as program directors at the Directorate for Education and Human Resources at the U.S. National Science Foundation (NSF), discuss fundable research questions for research in mathematics and science education. King et al. (2020) situate their discussion of fundable research questions in the context of writing successful educational research grant proposals. For them, fundable research questions must be transformative and significant with specific and clear constructs. In addition, they present examples of STEM education research questions from different types of research (Institute of Education Sciences [IES] \& NSF, 2013) and how the questions themselves direct specific design choices, methodologies, measures, study samples, and analytical models as well as how they can reflect the disciplinary orientations of the researchers. 
Hjalmarson and Baker (2020) take a quite different approach to discussing researchable questions for teacher professional development. They argue for the need to include mathematics specialists (e.g. mathematics coaches or mathematics teacher leaders) for studying teacher learning and development. To Hjalmarson and Baker (2020), researchable questions related to teacher professional learning should be selected by including mathematics specialists because of their role in connecting research and practice.

Sanchez (2020) discuss, in particular, the importance of replication studies in mathematics and the kinds of researchable questions that would be productive to explore within this category. With the increased acknowledgement of the importance of replication studies (Cai et al., 2018), Sanchez Aguilar has provided a useful typology of fundamental questions that can guide a replication study in mathematics (and science) education.

Schoenfeld (2020) is very direct in suggesting that researchable questions must advance the field and that these research questions must be meaningful and generative: "What is meant by meaningful is that the answer to the questions posed should matter to either practice or theory in some important way. What is meant by generative is that working on the problem, whether it is 'solved' or not, is likely to provide valuable insights" (pp. XX). Schoenfeld calls for researchers to establish research programsthat is, one not only selects meaningful research questions to investigate but also continues in that area of research to produce ongoing insights and further meaningful questions.

Stylianides and Stylianides (2020) argue that, collectively, researchers can and need to pose new researchable questions. The new researchable questions are worth investigating if they reflect the field's growing understanding of the web of potentially influential factors surrounding the investigation of a particular area. The argument that Stylianides and Stylianides (2020) use is very similar to Schoenfeld's (2020) generative criteria, but Stylianides and Stylianides (2020) explicitly emphasize the collective nature of the field's growing understanding of a particular phenomenon.

\section{Sources of Researchable Questions}

Research questions in science and mathematics education arise from multiple sources, including problems of practice, extensions of theory, and lacunae in existing areas of research. Therefore, through a research question's connections to prior research, it should be clear how answering the question extends the field's knowledge (Cai et al., 2019a). Across the papers in this special issue lies a common theme that researchable questions arise from understanding the area under study. Cai et al. (2020) take the position that the significance of researchable questions must be justified in the context of prior research. In particular, reviewers of manuscripts submitted for publication will evaluate if the study is adequately motivated. In fact, posing significant researchable questions is an iterative process beginning with some broader, general sense of an idea which is potentially fruitful and leading, eventually, to a wellspecified, stated research question (Cai et al., 2019a). Similarly, King et al. 
(2020) argue that fundable research questions should be grounded in prior research and make explicit connections to what is known or not known in the given area of study.

Sanchez (2020) suggest that it is time for the field of mathematics and science education research to seriously consider replication studies. Researchable questions related to replication studies might arise from the examination of the following two questions: (1) Do the results of the original study hold true beyond the context in which it was developed? (2) Are there alternative ways to study and explain an identified phenomenon or finding? Similarly, Hjalmarson and Baker (2020) specifically suggest two needs related to mathematics specialists in studies of professional development that drive researchable questions: (1) defining practices and hidden players involved in systematic school change and (2) identifying the unit of analysis and scaling up professional development.

Schoenfeld (2020) uses various examples to illustrate the origin of researchable questions. One of his (perhaps most familiar) examples is his decade-long research on mathematical problem solving. He elaborates on how answering one specific research question leads to another and another. In the context of research on mathematical proof, Stylianides and Stylianides (2020) also illustrate how researchable questions arise from existing research in the area leading to new researchable questions in the dynamic process of educational research. The arguments and examples in both Schoenfeld (2020) and Stylianides and Stylianides (2020) are quite powerful in the sense that this source of researchable questions facilitates the accumulation of knowledge for the given areas of study.

A related source of researchable questions is not discussed in this set of papers-unexpected findings. A potentially powerful source of research questions is the discovery of an unexpected finding when conducting research (Cai et al., 2019b). Many important advances in scientific research have their origins in serendipitous, unexpected findings. Researchers are often faced with unexpected and perhaps surprising results, even when they have developed a carefully crafted theoretical framework, posed research questions tightly connected to this framework, presented hypotheses about expected outcomes, and selected methods that should help answer the research questions. Indeed, unexpected findings can be the most interesting and valuable products of the study and a source of further researchable questions (Cai et al., 2019b).

Of course, researchable questions can also arise from established scholars in a given field - those who are most familiar with the scope of the research that has been done. For example, in 2005, in celebrating the 125th anniversary of the publication of Science's first issue, the journal invited researchers from around the world to propose the 125 most important research questions in the scientific enterprise (Kennedy, 2005). A list of unanswered questions like this is a great source for researchable questions in science, just as the 23 great questions in mathematics by Hilbert (1901-1902) spurred the field for decades. In mathematics and science education, one can look to research handbooks and compendiums. These volumes often include lists of unanswered research questions in the hopes of prompting further research in various areas (e.g. Cai, 2017; Clements, Bishop, Keitel, Kilpatrick, \& Leung, 2013; Talbot-Smith, 2013). 


\section{Alignment of Researchable Questions with the Conceptual Framework and Appropriate Research Methods}

Cai et al. (2020) and King et al. (2020) explicitly discuss the alignment of researchable questions with the conceptual framework and appropriate research methods. In writing journal publications or grant proposals, it is extremely important to justify the significance of the researchable questions based on the chosen theoretical framework and then determine robust methods to answer the research questions. According to Cai et al. (2019a), justification for the significance of the research questions depends on a theoretical framework: "The theoretical framework shapes the researcher's conception of the phenomenon of interest, provides insight into it, and defines the kinds of questions that can be asked about it" (p. 119). It is true that the notion of a theoretical framework can remain somewhat mysterious and confusing for researchers. However, it is clear that the theoretical framework links research questions to existing knowledge, thus helping to establish their significance; provides guidance and justification for methodological choices; and provides support for the coherence that is needed between research questions, methods, results, and interpretations of findings (Cai \& Hwang, 2019; Cai et al., 2019c).

Analyzing reviews for a research journal in mathematics education, Cai et al. (2020) found that the reviewers wanted manuscripts to be explicit about how the research questions, the theoretical framework, the methods, and the findings were connected. Even for manuscripts that were accepted (pending revisions), making explicit connections across all parts of the manuscript was a challenging proposition. Thus, in preparing manuscripts for publication, it is essential to communicate the significance of a study by developing a coherent chain of justification connecting researchable questions, the theoretical framework, and the research methods chosen to address the research questions.

\section{The Long Journey Has Just Begun with a First Step}

As the field of mathematics and science education matures, there is a need to take a step back and reflect on what has been done so that the field can continue to grow. This special issue represents a first step by reflecting on the posing of significant researchable questions to advance research in mathematics and science education. Such reflection is useful and necessary not only for the design of studies but also for the writing of research reports for publication. Most importantly, working on significant researchable questions cannot only contribute to theory generation about the teaching and learning of mathematics and science but also contribute to improving the impact of research on practice in mathematics and science classrooms.

To conclude, we want to draw readers' attention to a parallel between this reflection on research in our field and a line of research that investigates the development of school students' problem-posing and questioning skills in mathematics and science (Blonder, Rapp, Mamlok-Naaman, \& Hofstein, 2015; Cai, Hwang, Jiang, \& Silber, 2015; Cuccio-Schirripa \& Steiner, 2000; Hofstein, Navon, Kipnis, \& MamlokNaaman, 2005; Silver, 1994; Singer, Ellerton, \& Cai, 2015). Posing researchable questions is critical for advancing research in mathematics and science education. 
Similarly, providing students opportunities to pose problems is critical for the development of their thinking and learning. With the first step in this journey made, perhaps we can dream of something bigger further on down the road.

\section{References}

Blonder, R., Rapp, S., Mamlok-Naaman, R., \& Hofstein, A. (2015). Questioning behavior of students in the inquiry chemistry laboratory: Differences between sectors and genders in the Israeli context. International Journal of Science and Mathematics Education, 13(4), 705-732.

Cai, J. (Ed.). (2017). Compendium for research in mathematics education. Reston, VA: National Council for Teachers of Mathematics.

Cai, J., \& Hwang, S. (2019). Constructing and employing theoretical frameworks in (mathematics) education research. For the Learning of Mathematics, 39(3), 45-47.

Cai, J., Hwang, S., Hiebert, J., Hohensee, C., Morris, A., \& Robison, V. (2020). Communicating the significance of research questions: Insights from peer review at a flagship journal. International Journal of Science and Mathematics Education. https://doi.org/10.1007/s10763-020-10073-x.

Cai, J., Hwang, S., Jiang, C., \& Silber, S. (2015). Problem posing research in mathematics: Some answered and unanswered questions. In F. M. Singer, N. Ellerton, \& J. Cai (Eds.), Mathematical problem posing: From research to effective practice (pp. 3-34). New York, NY: Springer.

Cai, J., Morris, A., Hohensee, C., Hwang, S., Robison, V., Cirillo, M., . . . Hiebert, J. (2019a). Posing significant research questions. Journal for Research in Mathematics Education, 50(2), 114120. https://doi.org/10.5951/jresematheduc.50.2.0114.

Cai, J., Morris, A., Hohensee, C., Hwang, S., Robison, V., Cirillo, M., . . Hiebert, J. (2019b). So what? Justifying conclusions and interpretations of data. Journal for Research in Mathematics Education, 50(5), 470477. https://doi.org/10.5951/jresematheduc.50.5.0470.

Cai, J., Morris, A., Hohensee, C., Hwang, S., Robison, V., Cirillo, M., . . Hiebert, J. (2019c). Theoretical framing as justifying. Journal for Research in Mathematics Education, 50(3), 218224. https://doi. org/10.5951/jresematheduc.50.3.0218.

Cai, J., Morris, A., Hohensee, C., Hwang, S., Robison, V., \& Hiebert, J. (2018). The role of replication studies in educational research. Journal for Research in Mathematics Education, 49(1), 2-8. https://doi. org/10.5951/jresematheduc.49.1.0002.

Clements, M. A., Bishop, A., Keitel, C., Kilpatrick, J., \& Leung, K. S. F. (Eds.). (2013). Third international handbook of mathematics education research. New York, NY: Springer.

Cuccio-Schirripa, S., \& Steiner, H. E. (2000). Enhancement and analysis of science question level for middle school students. Journal of Research in Science Teaching, 37, 210-224.

Einstein, A., \& Infeld, L. (1938). The evolution of physics: The growth of ideas from early concepts to relativity and quanta. Cambridge, England: Cambridge University Press.

Hilbert, D. (1901-1902). Mathematical problems. Bulletin of the American Mathematical Society, 8, 437-479.

Hjalmarson, M. A., \& Baker, C. K. (2020). Mathematics specialists as the hidden players in professional development: Researchable questions and methodological considerations. International Journal of Science and Mathematics Education. https://doi.org/10.1007/s10763-020-10077-7.

Hofstein, A., Navon, O., Kipnis, M., \& Mamlok-Naaman, R. (2005). Developing students ability to ask more and better questions resulting from inquiry-type chemistry laboratories. Journal of Research in Science Teaching, 42, 791-806.

Inglis, M., \& Foster, C. (2018). Five decades of mathematics education research. Journal for Research in Mathematics Education, 49(4), 462-500.

Institute of Education Sciences \& National Science Foundation. (2013). Common guidelines for education research and development. Washington, DC: Authors.

Kennedy, D. (2005). Editorial. Science, 310(5749), 787. https://doi.org/10.1126/science.310.5749.787b.

King, K., Ochsendorf, R. J., Solomon, G. E. A., \& Sloane, F. C. (2020). Posing fundable questions in mathematics and science education. International Journal of Science and Mathematics Education. https://doi.org/10.1007/s10763-020-10088-4.

Mosteller, F. (1980). The next 100 years of science. Science, 209(4452), 21-23. https://doi.org/10.1126 /science. 7280662 . 
Sanchez, M. (2020). Replication studies in mathematics education: What kind of questions would be productive to explore? International Journal of Science and Mathematics Education. https://doi. org/10.1007/s10763-020-10069-7.

Schoenfeld, A. (2020). On meaningful, researchable, and generative questions. International Journal of Science and Mathematics Education. https://doi.org/10.1007/s10763-020-10068-8.

Silver, E. A. (1994). On mathematical problem posing. For the Learning of Mathematics, 14(1), 19-28.

Singer, F. M., Ellerton, N., \& Cai, J. (2015). Mathematical problem posing: From research to effective practice. New York, NY: Springer.

Stylianides, G. J., \& Stylianides, A. J. (2020). Posing new researchable questions as a dynamic process in educational research. International Journal of Science and Mathematics Education. https://doi. org/10.1007/s10763-020-10067-9.

Talbot-Smith, M. (2013). Handbook of research on science education. Waltham, Massachusetts, Focal Press. 